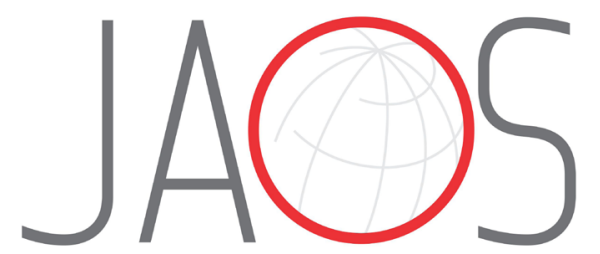

JOURNAL OF APPLIED ORAL SCIENCE

\title{
Effect of passive ultrasonic activation on microorganisms in primary root canal infection: a randomized clinical trial
}

\section{Abstract}

Esteban Isai Flores OROZCO

Cassia Cestari TOIA ${ }^{1}$

Daiana CAVALLI ${ }^{1}$

Rayana Duarte KHOURY ${ }^{1}$

Flávia Goulart da Rosa CARDOSO ${ }^{1}$

Eduardo BRESCIANI ${ }^{1}$

Marcia Carneiro VALERA ${ }^{1}$
Submitted: February 18, 2019 Modification: June 19, 2019 Accepted: July 16, 2019

Corresponding address: Marcia Carneiro Valera Universidade Estadual Paulista (UNESP) - Instituto de Ciências e Tecnologia - Departamento de Odontologia Restauradora - Divisão de Endodontia - Av. Eng Francisco José Longo, 777 - 12245-000 São José dos Campos - SP - Brasil. Phone: (55) 1239479400 - Fax: (55) 1239479000 e-mail: marcia@ict.unesp.br
Objective: This clinical study sought to evaluate the effectiveness of passive ultrasonic activation (PUA) in eliminating microorganisms in primary endodontic infection (PEI) after instrumentation of root canals using microbiological culture and checkerboard DNA-DNA hybridization. Methodology: Twenty root canals with PEI and apical periodontitis were selected. The root canals were instrumented and then randomly divided into 2 groups, according to the irrigation method: PUA and conventional needle irrigation (CNI). Microbiological samples were collected before instrumentation (S1), after instrumentation (S2) and after irrigation with $17 \%$ EDTA (S3). The samples were subjected to anaerobic culture technique and checkerboard DNA-DNA hybridization analysis. Results: A statistically significant difference was found between CNI (23.56\%) and PUA (98.37\%) regarding the median percentage values for culturable bacteria reduction $(p<0.05)$. In the initial samples, the most frequently detected species was S. constellatus (50\%), and after root canal treatment was E. faecalis (50\%). Conclusion: Both treatments significantly decreased the number of bacterial species compared with the initial sample. However, no statistical difference in the total microbial load between PUA and CNI groups was detected. The number of cultivable anaerobic bacteria reduced significantly using PUA, and the bacterial composition and number of bacterial species after using either CNI or PUA was similar.

Keywords: Root canal therapy. Bacteria. Ultrasound.
'Universidade Estadual Paulista (UNESP), Instituto de Ciências e Tecnologia, Departamento de Odontologia Restauradora, São José dos Campos, São Paulo, Brasil. 


\section{Introduction}

The successful treatment of apical periodontitis depends on the maximum decrease in microorganisms and their by-products in root canals. Root canal preparation is associated with an irrigating solution to obtain maximal reduction in microbial load inside the root canal to prevent or eliminate apical periodontitis. ${ }^{1-3}$ The irrigant used during instrumentation is supposed to act as a cleaning, disinfectant and lubricant agent. ${ }^{4}$ Sodium hypochlorite $(\mathrm{NaOCl})$ is the most widely used irrigant in endodontics, especially due to its antimicrobial activity ${ }^{6}$ and organic tissue dissolution capacity. ${ }^{4,5}$ In addition to $\mathrm{NaOCl}$, the use of ethylenediaminetetraacetic acid (EDTA) is a common practice in endodontic treatment to remove the inorganic component or smear layer left in the canal during endodontic treatment. ${ }^{6}$

However, the root canal system has some anatomical complexities such as apical ramifications, isthmus, and dentinal tubules, which may impede full disinfection. Studies have shown the presence of microorganisms in necrotic teeth not only in the main canal, but also throughout the root canal system, even after chemomechanical preparation. ${ }^{7-10}$ The remaining bacteria may influence the treatment result and can be associated with persistent apical periodontitis. ${ }^{11}$ Thus, all efforts have been made to obtain maximum bacterial elimination from the root canals before filling. ${ }^{3}$

Conventional needle irrigation (CNI) is the most commonly performed irrigation system worldwide. Despite its good control over the irrigant delivery, this technique seems to be unable to flush out organic and inorganic tissue remnants and to clean the apical third of the root canal. ${ }^{12}$ Several adjunctive approaches have been developed to overcome the limitations of CNI. Passive ultrasonic activation (PUA) has been suggested to enhance root canal disinfection. ${ }^{4}$ This technique improves the cleanliness of instrumented and uninstrumented areas using ultrasonic activation of the irrigant, which is expected to aid the delivery of irrigants into difficult-to-reach areas. ${ }^{13}$

Despite the existence of several ex vivo studies assessing the antimicrobial effect of ultrasonic activation with $\mathrm{NaOCl}$ as an adjunctive step, they have been inconclusive regarding bacterial load reduction. While some studies demonstrate better efficacy using the ultrasonic activation protocol, ${ }^{14}$ others report absence of significant difference. ${ }^{15,16}$ In clinical study, randomized clinical trials are the best way to study the safety and efficacy of new interventions and treatments. ${ }^{17}$ Only a few clinical studies have evaluated the effectiveness of the ultrasonic activation approach in improving significantly the disinfection after biomechanical procedure. ${ }^{18,19}$ However, the extrapolation of outcomes from ex vivo studies to the clinical settings must be prudent. Although the complete eradication of microorganisms does not occur, some studies have reported a high frequency of negative cultures, ${ }^{19}$ which may be related to the limitations of culture methods, including low sensitivity and inability to detect non-cultivable bacterial species. ${ }^{20}$ Therefore, using molecular approaches is essential to analyze antimicrobial effects of endodontic procedures to overcome such issues, also providing a more accurate sight of the microbiological conditions. ${ }^{20,21}$

Only one randomized clinical trial assessing the antimicrobial effect of ultrasonic activation by molecular-based methods has been reported. ${ }^{18}$ Therefore, this randomized clinical study sought to assess the antibacterial effects of final irrigation protocols using PUA or CNI after biomechanical preparation with single-file reciprocation technique, using $2.5 \% \mathrm{NaOCl}$, in teeth with primary endodontic infection using culture and molecular-based methods. Considering the advantage of volumetric analysis of bone destruction determined by Cone Beam Computed Tomography (CBCT) image, this clinical study also assessed the clinical outcomes by measuring the periapical lesion reduction with a 18-month follow-up by CBCT analysis.

\section{Methodology}

\section{Patient selection}

This randomized clinical trial was performed at São José dos Campos Dental School, São José dos Campos, $\mathrm{SP}$, Brazil, and was approved by the local Institutional Review Board (CEP: 83576418.0.0000.0077). The clinical trial was registered at the Brazilian Clinical Trials Registry (http://ensaiosclinicos.gov.br) Primary ID:RBR-7CXWG5. Considering a 99\% reduction in the anaerobic bacteria count ${ }^{22}$ as a standard reduction; $5 \%$ significance level, $80 \%$ power, equivalence limit of $15 \%$ and sample size of 10 patients per group 
were required. Power was estimated using the website https://sealedenvelope.com/power/binaryequivalence/, under binary outcome and equivalence trial option. From 157 patients examined, 20 requiring primary endodontic treatment were selected for this study (Figure 1 ). The study included upper and lower single rooted teeth having primary endodontic infection with radiographic evidence of apical periodontitis and intact pulp chamber walls. The diagnosis of pulpal necrosis was confirmed by a negative response to the cold test. Patient age ranged from 18 to 60 years (50\% were male and $50 \%$ female). Among the 20 unirradicular teeth included in the study, 7 were upper lateral incisors (7/20), 3 lower central incisors (3/20), 3 lower lateral incisor (3/20), 2 lower canines $(2 / 20), 3$ lower first premolars $(3 / 20)$ and 2 lower second premolars $(2 / 20)$. All patients were volunteers and signed an informed consent form. The exclusion criteria were: tooth that could not be isolated with rubber dam, tooth with periodontal pockets deeper than $4 \mathrm{~mm}$, and patients who had received antibiotic treatment during the past 3 months or had any general disease. A detailed dental history was requested from each patient.

Clinical signs and symptoms were recorded, and all patients included were subjected to Cone Beam Computed Tomography (CBCT) to determine the volume, in cubic millimeters, of periapical bone resorption before the endodontic treatment. Outcome measures were defined by periapical lesion volume reduction after a 18-month follow-up, and sign and symptom remission (Figure 6).

\section{Sampling procedures}

Instruments and all materials used in this study were treated with ${ }^{60} \mathrm{Co}$ gamma radiation (20 kGy for 6 hours) (EMBRARAD, Cotia, SP, Brazil). Samples were collected under aseptic conditions. The tooth was isolated with a rubber dam and had its crown and surrounding structures disinfected with $30 \% \mathrm{H}_{2} \mathrm{O}_{2}$ [volume/volume (V/V)] for 30 seconds, followed by $5.25 \% \mathrm{NaOCl}$ for the same period and then inactivated with $5 \%$ sodium thiosulfate. ${ }^{9}$

A two-stage access preparation was performed without using water spray but under manual irrigation with sterile/apyrogenic saline solution by using a sterile/apyrogenic high-speed diamond bur. The first stage was performed to promote a major removal of contaminants, including carious lesion and restoration. In the second stage, the access cavity was again disinfected with $5.25 \% \mathrm{NaOCl}$ and subsequently inactivated with $5 \%$ sodium thiosulfate before entering the pulp chamber. All procedures were performed aseptically.

Root canal samples were taken as follows: 3 sterile paper points were consecutively introduced into the full length of the canal, which was determined radiographically, and retained in position for 60 seconds, and then immediately placed into a sterile tube containing $1 \mathrm{~mL}$ VMGA III (Viability Medium Göteborg Agar) transport medium for microbiologic analysis. ${ }^{23}$

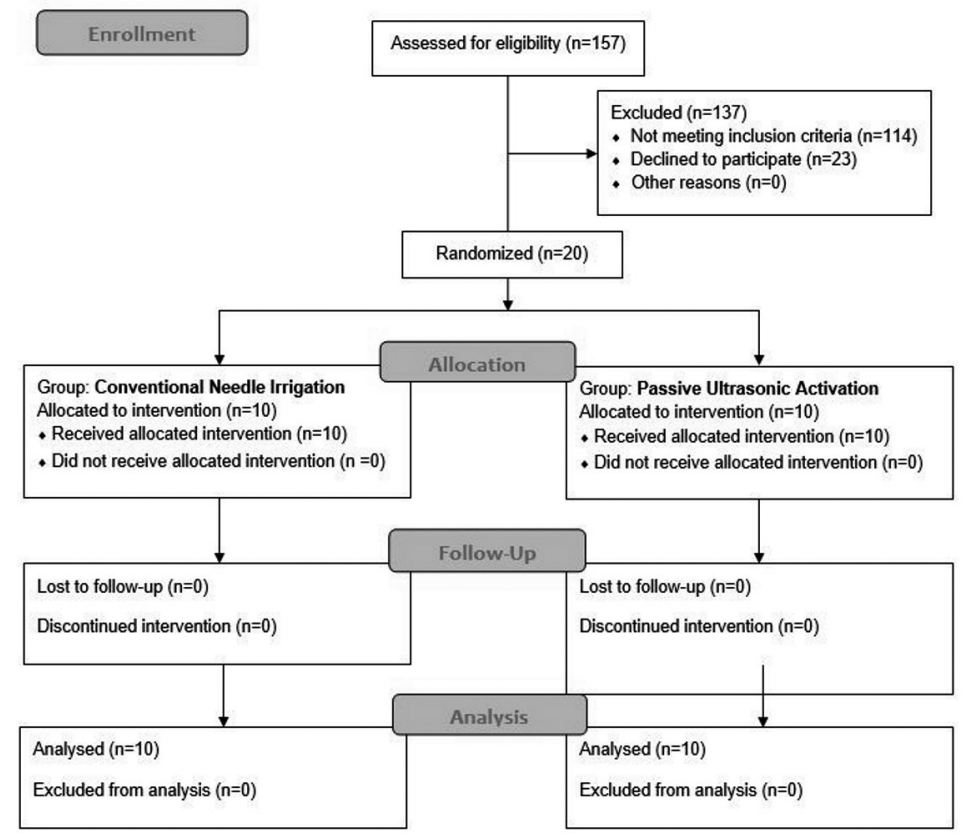

Figure 1- CONSORT flow diagram 
After the first sample (S1 - baseline), the instrumentation was performed by one single operator using single-file reciprocation technique. According to the manufacturer's instructions, Reciproc R40 files (40.06) (VDW GmbH, Munich, Germany) were selected after confirming that for all teeth included the initial apical instrument was ISO size \#20 hand file, which reached passively to working length. The file was adapted to an electric motor (VDW Silver, VDW $\mathrm{GmbH}$, Munich, Germany) using preset adjustments. The instrument was introduced into the root canal until resistance was felt and then activated. Next, the instrument was apically moved using in-andout pecking motions, with approximately $3 \mathrm{~mm}$ in amplitude by using light apical pressure. After 3 pecking motions, the instrument was removed and cleaned. Between each third (cervical, middle, and apical), $8 \mathrm{~mL}$ of $2.5 \% \mathrm{NaOCl}$ was used to neutralize the content inside the root canal. The working length (WL) $(-1 \mathrm{~mm})$ was determined by using an apex locator (RomiApex A-15; Romidan Dental Solution, Kiryat-Ono, Israel) and confirmed by a periapical digital radiograph. Likewise, apical debridement was performed with a K-file size \#30, which was extended $1 \mathrm{~mm}$ beyond this area. The root canal instrumentation was completed in a single visit in all cases, with a total of $24 \mathrm{~mL}$ of $2.5 \% \mathrm{NaOCl}$ in both groups.

Subsequently, the patients were randomly distributed before receiving endodontic treatment with either CNI or PUA technique. The participants were divided into 2 groups by using the simple randomization method according to the CONSORT 2010 (Consolidated Standards of Reporting Trials), : an independent researcher prepared envelopes, including writing the technique name (either CNI or PUA) on a sheet of paper inside. Another researcher opened the envelope just before the procedure and informed the operator to perform the treatment with the technique written on the paper. All participants and laboratory raters were kept blind.

\section{PUA Group}

The root canals were irrigated with $4 \mathrm{~mL}$ of $2.5 \%$ $\mathrm{NaOCl}$ delivered by using a 31 gauge $\times 27 \mathrm{~mm}$ side port needle (NaviTip, Ultradent Products Inc., South Jordan, UT, USA) inserted up to $1 \mathrm{~mm}$ short of the $W L$, with PUA being performed for 30 seconds. The irrigating solution was renewed with $4 \mathrm{~mL}$ of $2.5 \%$ $\mathrm{NaOCl}$ and PUA was resumed for 30 additional seconds. For inactivation of $2.5 \% \mathrm{NaOCl}$, the canal was irrigated with $5 \mathrm{~mL}$ of $5 \%$ sodium thiosulfate, followed by irrigation with $10 \mathrm{~mL}$ of saline solution. The second sample was collected (S2) in the same manner as the first sample (S1). The smear layer was removed by rinsing the canal with $17 \%$ EDTA, which remained inside the canal for 2 minutes and then was activated with PUA for 1 minute. After additional 2 minutes inside the root canal, $17 \%$ EDTA was removed by irrigation with $10 \mathrm{~mL}$ of saline solution. After the procedure, the third sample was collected (S3). The ultrasonic

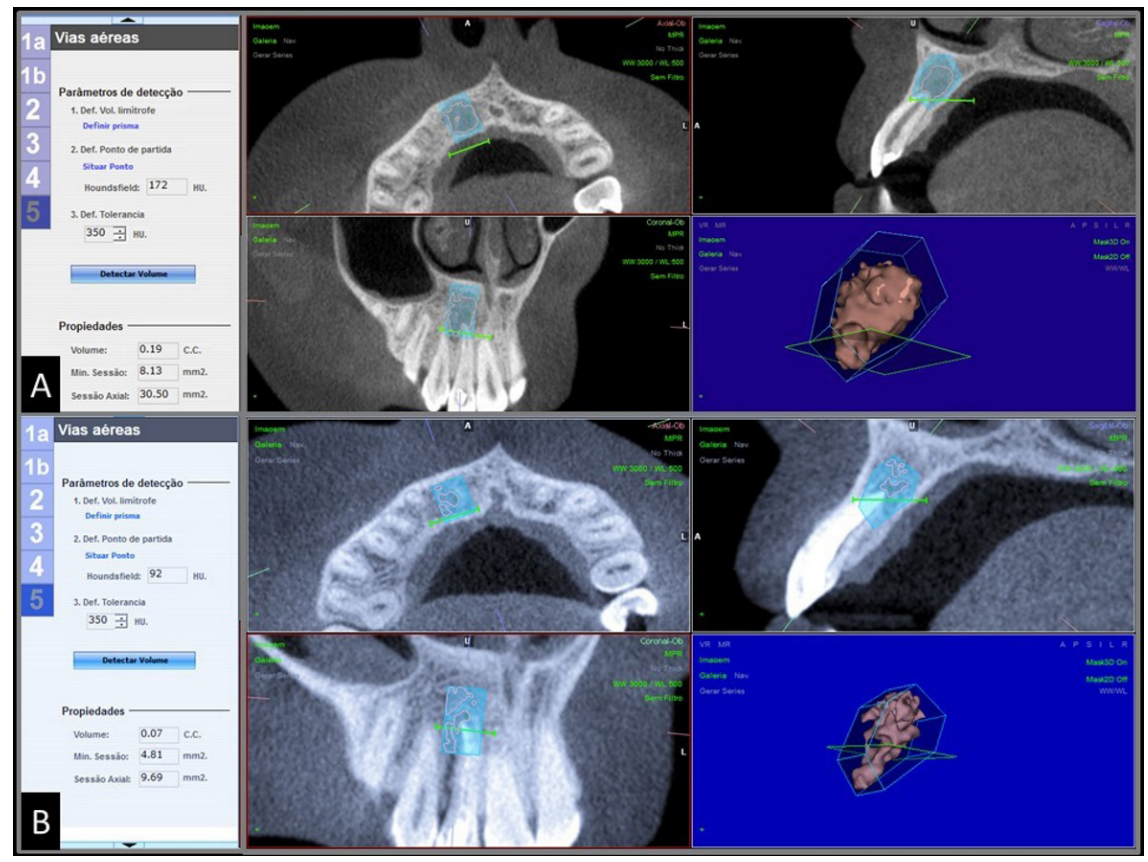

Figure 6- DICOM data of (A) preoperative and (B) 18-month follow-up analysis transferred to NEMOTEC ${ }^{\circledR}$ software (Madrid, Spain), and $3 \mathrm{D}$ reconstruction of periapical lesion 
activation was performed with a \#20:01 non-cutting tip (E1 Irrisonic, Helse, São Paulo, SP, Brazil) and piezoelectric ultrasonic device (ALT - Equipamentos Médicos e Odontológicos, Ribeirão Preto, SP, Brazil) at $1000 \mathrm{~Hz}$ low power. The ultrasonic instrument was used at $1 \mathrm{~mm}$ short of the $\mathrm{WL}$, avoiding contact with the root canal walls (Figure 2 ).

\section{CNI Group}

Similar to the PUA protocol; in this group, root canal was irrigated with $8 \mathrm{~mL}$ of $2.5 \% \mathrm{NaOCl}$ by using a 31 gauge $\times 27 \mathrm{~mm}$ side port needle (NaviTip, Ultradent, South Jordan, UT, USA), inserted up to $1 \mathrm{~mm}$ short of the $\mathrm{WL}$, and $17 \%$ EDTA remained inside the root canal for 4 minutes and manually agitated for 1 additional minute. The $2.5 \% \mathrm{NaOCl}$ inactivation and $17 \%$ EDTA removal were performed in the same manner as described for PUA group. No ultrasonic activation was performed in this group (Figure 2).

Each group received a total of $8 \mathrm{~mL}$ of $2.5 \%$ $\mathrm{NaOCl}$ in the final irrigation protocol, and $17 \%$ EDTA remained inside the root canal for 5 minutes (Figure 2).

\section{Culture procedure (CFU/mL)}

The transport media containing the root canal samples were thoroughly shaken for 60 seconds (Vortex; Marconi, Piracicaba, SP, Brazil). Serial 10-fold dilutions were made up to $10^{-3}$. Fifty microliters of the serial dilutions were plated onto $5 \%$ defibrinated sheep blood fastidious anaerobe agar (FAA; Lab M, Bury, UK) by using sterile plastic spreaders to culture nonselective obligate anaerobes and facultative anaerobes. The plates were incubated at $37^{\circ} \mathrm{C}$ in anaerobic atmosphere for up to 14 days. After this period, colony-forming units (CFUs) were visually quantified for each plate.

\section{Microbiological assessment: checkerboard DNA-DNA hybridization}

Three hundred microliters of VMGA containing the root canal samples was transferred to another sterile tube. Subsequently, the tubes were centrifuged at $8000 \mathrm{rpm}$ for 5 minutes. The supernatant was then discarded, and the pellet resuspended at $150 \mathrm{~mL}$ Tris-EDTA buffer $[10 \mathrm{mmol} / \mathrm{L}$ tris (hydroxymethyl) aminomethane (Tris)- $\mathrm{HCl}, 1 \mathrm{mmol} / \mathrm{L}$ EDTA, $\mathrm{pH}=7.6]$.

\section{Sample 1 - Baseline}
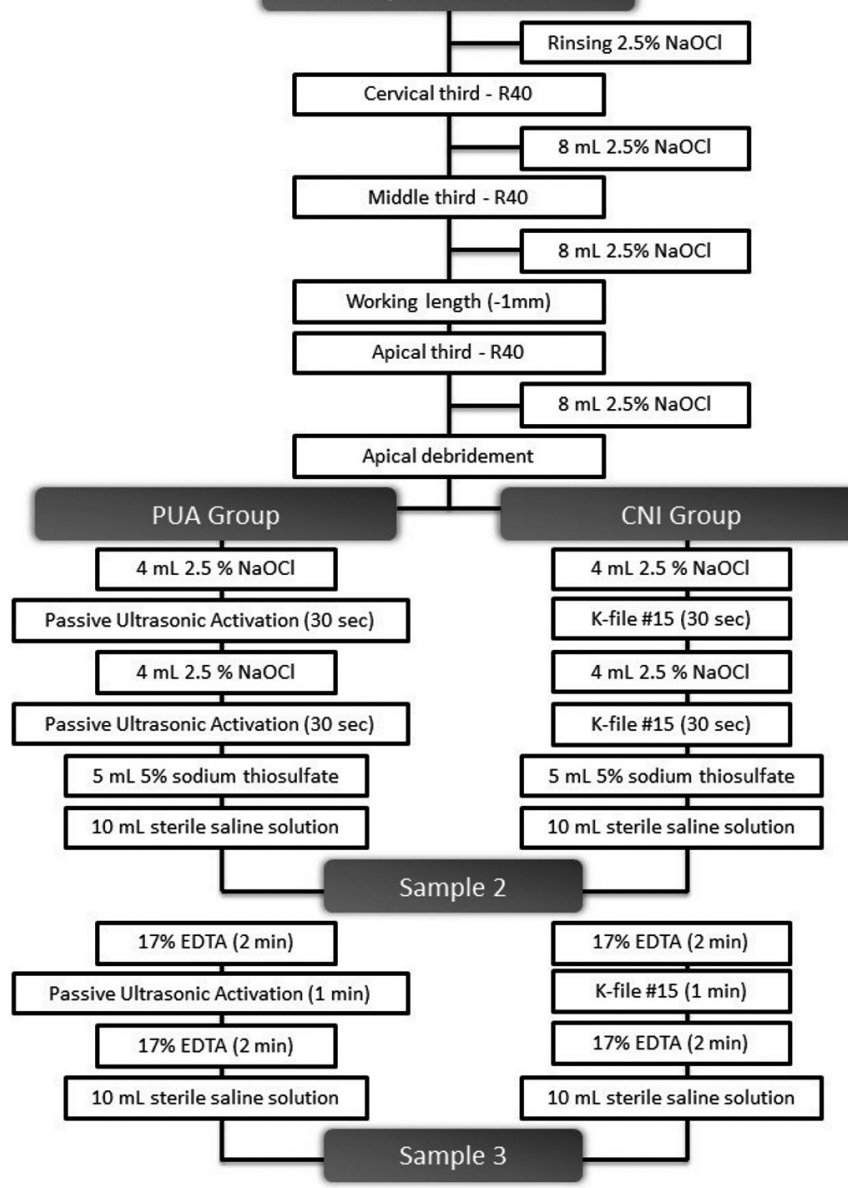

Figure 2- Flow diagram of interventions and sampling procedures 
Next, $100 \mathrm{~mL} 0.5 \mathrm{~mol} / \mathrm{L} \mathrm{NaOH}$ was added to each tube, and the samples were frozen at $-20^{\circ} \mathrm{C}$ until they were processed.

Presence, levels, and proportions of 40 bacterial species (Figure 3) were determined by the checkerboard DNA-DNA hybridization method described by Socransky, et al. ${ }^{24}$ (1994). The DNA probes were prepared by using the DIG DNA Labeling Kit (Roche Diagnostics, Indianapolis, IN, USA) and frozen until use. Next, the samples were boiled for 10 minutes, and $800 \mathrm{~mL}$ of $5 \mathrm{~mol} / \mathrm{L}$ ammonium acetate were added to promote bacterial lyses and consequent suspension of DNA in solution. A nylon membrane $(15 \times 15 \mathrm{~cm})$ with a positive charge (Amersham Biosciences, Chicago, IL, USA) was placed in a Minislot 30 apparatus (Immunetics, Cambridge, MA, USA), and $1000 \mathrm{~mL}$ of each suspension was placed into the extended slots of the Minislot 30 and fixed to the membrane by baking it at $120^{\circ} \mathrm{C}$ for 20 minutes. In each membrane, 28 samples were placed, and the last 2 channels of the Minislot 30 were reserved for placement of controls, containing a mixture of species of microorganisms that have been investigated by DNA probes at 2 concentrations (i.e., $10^{5}$ and $10^{6}$ ) of bacterial cells.
A Miniblotter 45 apparatus (Immunetics, Cambridge, MA, USA) was used to hybridize the digoxigeninlabeled whole-genomic DNA probes perpendicular to the lanes of the clinical samples. Bound probes were detected using phosphatase conjugated antibodies to digoxigenin and chemiluminescence (CDP-Star Detection Reagent, GE Healthcare Limited, Chicago, $I L$, USA). The membranes were placed under a radiographic film (AGFA-IBF, Duque de Caxias, RJ, Brazil) for almost 60 minutes. The films were processed right after. Each probe produced a certain type of signal, which was visually compared with the signals produced by the probes in the 2 controls containing $10^{5}$ and $10^{6}$ bacterial cells. The signals were coded into 6 different classes according to the following count levels: 0 : not detected, 1 : $<10^{5}$ cells, 2 : nearly $10^{5}$ cells, 3 : between $10^{5}$ and $10^{6}$ cells.

\section{CBCT analysis: periapical lesion volume (cubic millimeters)}

The CBCT scannings were performed using the i-cat Classic (Imaging Science International, Hatfield, PA, USA) at São Paulo State University (UNESP), Institute of Science and Technology, São José dos Campos,

\begin{tabular}{|c|c|c|c|c|c|}
\hline Species & Strain & Gram & Species & Strain & Gram \\
\hline Actinomyces israelli & 12102 & + & Leptotrichia buccalis & 14201 & - \\
\hline Actinomyces odontolyticus & 17929 & + & Neisseria mucosa & 19696 & - \\
\hline Actinomyces oris & 43146 & + & Parvimonas micra & 33270 & + \\
\hline $\begin{array}{l}\text { Aggregatibacter } \\
\text { Actinomycetemcomitans }(a+b)\end{array}$ & 43718 e 29523 & - & Porphyromonas endodontalis & 35406 & - \\
\hline Campylobacter gracilis & 33236 & - & Porphyromonas gingivalis & 33277 & - \\
\hline Campylobacter rectus & 33238 & - & Prevotella intermédia & 25611 & - \\
\hline Campylobacter showae & 51146 & - & Prevotella melaninogenica & 25845 & - \\
\hline Capnocytophaga gingivalis & 33624 & - & Prevotella nigrescens & 33563 & - \\
\hline Capnocytophaga ochracea & 33596 & - & Propionibacterium acnes $(I+I I)$ & 11827 e 11282 & + \\
\hline Capnocytophaga sputigena & 33612 & - & Selemonas noxia & 43541 & - \\
\hline Eikenella corrodens & 23837 & - & Streptococcus anginosus & 33397 & + \\
\hline Enterococcus faecalis & 29212 & + & Streptococcus constellatus & 27823 & + \\
\hline Enterococcus faecium & 6569 & + & Streptococcus gordonii & 10558 & + \\
\hline Eubacterium nodatum & 33099 & + & Streptococcus intermedius & 27335 & + \\
\hline Eubacterium saburreum & 33271 & + & Streptococcus mitis & 49456 & + \\
\hline $\begin{array}{l}\text { Fusobacterium nucleatum ssp } \\
\text { Nucleatum }\end{array}$ & 25586 & - & Streptococcus sanguinis & 10556 & + \\
\hline $\begin{array}{l}\text { Fusobacterium nucleatum ssp } \\
\text { Polymorphum }\end{array}$ & 10953 & - & Tannerella forsythia & 43037 & - \\
\hline $\begin{array}{l}\text { Fusobacterium nucleatum ssp } \\
\text { Vincentii }\end{array}$ & 49256 & - & Treponema denticola & B1 & - \\
\hline Fusobacterium periodonticum & 33693 & - & Treponema socranskii & S1 & - \\
\hline Gemella morbillorum & 27824 & + & Veillonela parvula & 10790 & - \\
\hline
\end{tabular}

Figure 3- Bacterial strains used for the development of DNA probes 
Brazil. The volume of periapical bone resorption was quantified by following the reconstruction parameters previously described by Cardoso, et al. ${ }^{8}$ (2015).

\section{Statistical analysis}

Data were typed into an Excel (Microsoft, Redmond, WA, USA) spreadsheet twice and analyzed with the STATISTICA 8.0 software (StatSoft Inc, Tulsa, OK, USA). Data did not present normal distribution, thus General Linear Model test was used to compare the effectiveness of endodontic treatment along the three sampling stages, in terms of the number of CFUs/mL. Regarding the number of detected bacterial species, data presented normal distribution and were subjected to 2-way repeated ANOVA test. The total bacterial load was analyzed by the General Linear Model. Multiple comparison tests were performed when detecting differences. For all tests, 5\% significance level, $\mathrm{p}<0.05$, was considered.

\section{Results}

\section{Culture procedure}

Bacteria were found in all initial samples (20/20), with median values of $2.4 \times 10^{5} \mathrm{CFU} / \mathrm{mL}\left(20-1.8 \times 10^{6}\right.$ $\mathrm{CFU} / \mathrm{mL}$ ). A statistically significant difference was found in the median percentage values for the reduction in cultivable bacteria $(p<0.05)$ between CNI (23.56\%) and PUA (98.37\%), producing $30 \%$ and $80 \%$ root canals free of cultivable bacteria in CNI and PUA group, respectively, in endodontic treatment (S3). No differences were found between S2 and S3 ( $p>0.05)$. The analysis results (CFUs/mL) are shown in Table 1.

\section{Checkerboard DNA-DNA hybridization}

The results of the checkerboard DNA-DNA analysis revealed that the 40 DNA bacterial probes tested were reactive with at least 1 or more clinical samples in S1. All root canals investigated showed bacterial signals for at least 1 of the 40 DNA bacterial probes tested in S1 (baseline), with 1 to 18 (mean=9.6) bacterial species per root canal. The most frequently detected species were S. constellatus (50\%), E. faecalis (45\%), F. nucleatum SP (45\%), P. gingivalis $(45 \%)$, P. melaninogenica $(45 \%)$ and $S$. intermedius $(45 \%)$. Frequency and DNA concentration of the each bacterial species investigated in S1 are shown in Figure 4. The mean number of bacterial species in $\mathrm{S} 1$ was $9 \pm 3.8$ and $10.2 \pm 5.9$, respectively, when comparing PUA with CNI (Table 2). The number of bacterial species ranged from 1 to 23 (mean=9.6) in samples collected after biomechanical preparation with single-file reciprocation technique using $2.5 \% \mathrm{NaOCl}$ (S2). The most frequently detected species was $E$. faecalis (55\%), L. buccalis (50\%), P. gingivalis (50\%), A. actinomycetemcomitans (45\%), P. acnes (45\%) and $S$. constellatus (45\%). No statistical difference was observed in the number of detected species or in the total bacterial load between $\mathrm{S} 1$ and $\mathrm{S} 2$ ( $p>0.05)$. Frequency and DNA concentration of each bacterial species investigated in S2 are shown in Figure 4. The mean number of bacterial species in S2 was $10.7 \pm 6.7$ and $8.6 \pm 6.9$, respectively, when comparing PUA and CNI, as shown in Table 2. S. constellatus, $P$. gingivalis and $A$. actinomycetemcomitans were the most frequently detected species in PUA group; and $F$. nucleatum sp. vicentii, L. buccalis and $S$. mitis in CNI group. No statistical difference was detected ( $p>0.05$ ).

After endodontic treatment, $\mathrm{S3}$, the number of bacterial species ranged from 1 to 23 (mean=8.7). $E$. faecalis was the most frequently detected species $(50 \%)$. No statistical difference in the number of detected species or the total bacterial load between S2 and S3 ( $p>0.05)$ was observed. The mean number

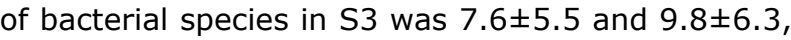
respectively, when comparing PUA with CNI (Table $2)$, without statistical difference between the groups $(p>0.05)$. Figure 5 shows the difference between the groups in the prevalence of microorganisms. A significantly greater reduction in the number of bacterial species and in the total bacterial load was observed in the final sample (S3) with the use of PUA protocol, completely eliminating 14 bacterial species

Table 1- Effectiveness of PUA and CNI protocol in removing cultivable bacteria (CFUs/mL) in primary endodontic infection (Uppercase Different columns; lowercase - different rows)

\begin{tabular}{cccc}
\hline Final Irrigation Protocol & \multicolumn{3}{c}{ Cultivable Bacteria (CFUs/mL) - Mean \pm SD } \\
& Before treatment (S1) & After NaOCl irrigation (S2) & After EDTA irrigation (S3) \\
\hline PUA $^{*}$ & $2.58 \times 10^{5} \pm 4.70 \times 10^{5 \mathrm{Aa}}$ & $6 \pm 19^{\mathrm{Bb}}$ & $42 \pm 119^{\mathrm{Bb}}$ \\
$\mathrm{CN}^{\star *}$ & $2.31 \times 10^{5} \pm 4.70 \times 10^{5 \mathrm{Aa}}$ & $5.72 \times 10^{3} \pm 1.10 \times 10^{4 \mathrm{Ab}}$ & $1.76 \times 10^{3} \pm 3.31 \times 10^{3 \mathrm{Ab}}$ \\
\hline
\end{tabular}

* PUA - Passive Ultrasonic Activation; ${ }^{*} \mathrm{CNI}$ - Conventional Needle Irrigation 

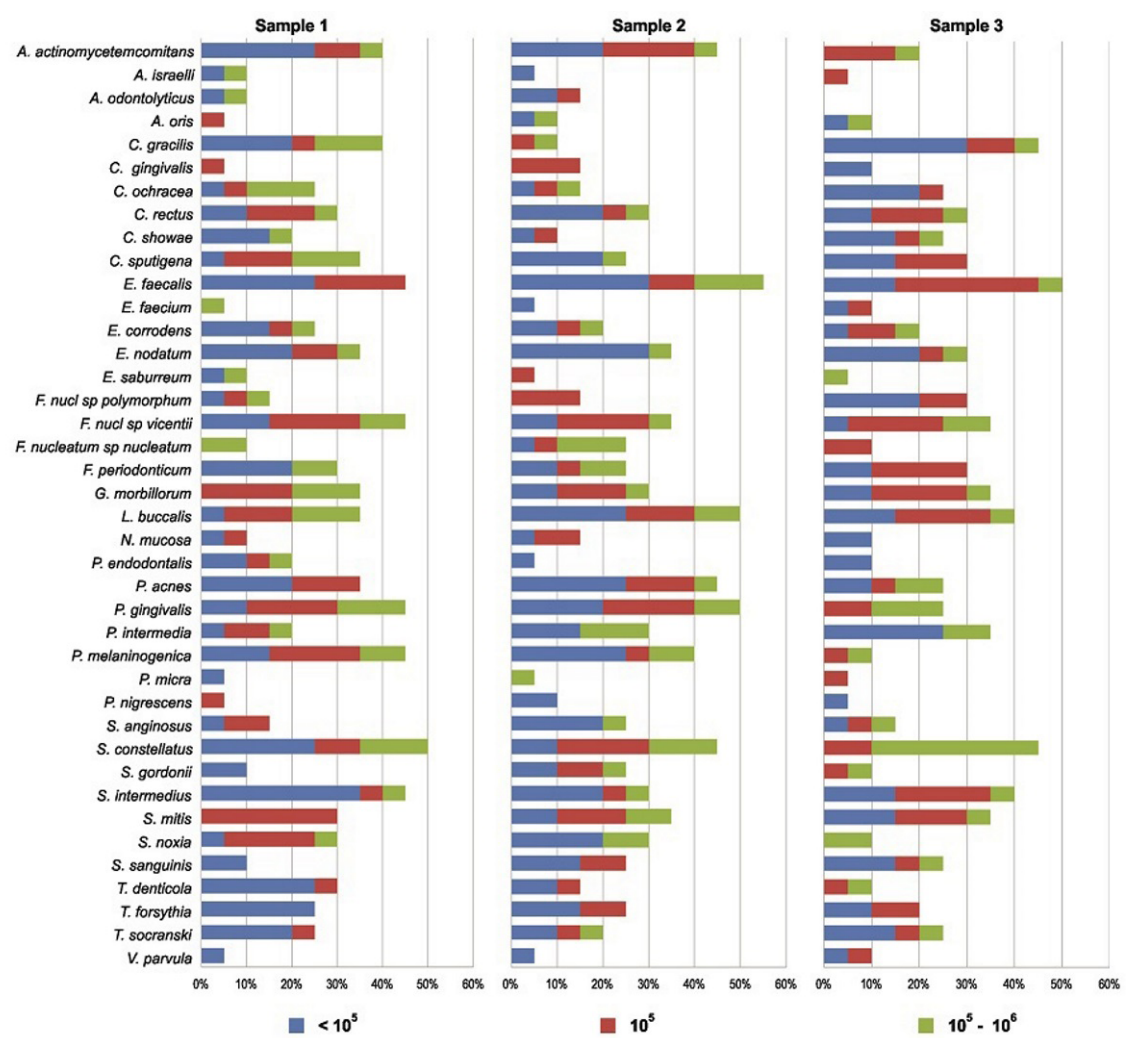

Figure 4- Stacked bar chart of frequency and DNA concentration of individual bacterial species investigated before root canal treatment (S1), and after instrumentation (S2 and S3). The total length of each bar indicates the percentage of positive samples. Different colors within each bar indicate the percentage of samples containing different concentrations of bacterial DNA

Table 2- Effectiveness of PUA and CNI protocol in removing bacterial species in primary endodontic infection (Uppercase - Different columns; lowercase - different rows)

\begin{tabular}{cccc}
\hline Final Irrigation Protocol & \multicolumn{3}{c}{ Number of Bacterial Species - Mean \pm SD } \\
& \multicolumn{2}{c}{ Checkerboard DNA-DNA Hybridization } \\
& Before treatment (S1) & After NaOCI irrigation (S2) & After EDTA irrigation (S3) \\
\hline $\mathrm{PUA}^{*}$ & $9 \pm 3.8^{\mathrm{Aa}}$ & $10.7 \pm 6.7^{\mathrm{Aa}}$ & $7.6 \pm 5.5^{\mathrm{Aa}}$ \\
$\mathrm{CNI}^{* *}$ & $10.2 \pm 5.9^{\mathrm{Aa}}$ & $8.6 \pm 6.9^{\mathrm{Aa}}$ & $9.8 \pm 6.3^{\mathrm{Aa}}$ \\
\hline
\end{tabular}

* PUA - Passive Ultrasonic Activation; ${ }^{* *} \mathrm{CNI}$ - Conventional Needle Irrigation

when comparing with CNI group, which completely eliminated only 5 species.

\section{CBCT analysis: periapical lesion volume (cubic millimeters)}

The measurement of the outcome was defined by CBCT analysis with a 18-month follow-up. Four patients from the PUA group were absent from the recall visits. The reduction was detected for both treatments $(p<0.043)$, considering the initial lesion volume. The mean final volumes were $39.0 \pm 45.3$ and 39.3 \pm 27.9 , for CNI and PUA, respectively. No differences between the groups were detected at this follow-up $(p=0.614)$ (Table 3$)$.

\section{Discussion}

In this randomized clinical trial, PUA or CNI were assessed as final irrigation protocols. PUA has been suggested as an adjunctive procedure to increase the tissue dissolution ${ }^{25}$ and, consequently, disinfection after instrumentation. Its benefits rely on the transmission of acoustic energy from a "noncutting" and oscillating tip to an irrigant inside the root canal. The energy transmitted might lead to an acoustic streaming, cavitation, and/or warming of the irrigating substance, expanding its spectrum of action, especially on microorganisms in difficult-to-reach areas. ${ }^{26,27}$

This study showed the presence of cultivable bacteria in all initial samples (S1). Data showed the use of both protocols reduced the number of cultivable bacteria after single-file reciprocation technique, using 
$2.5 \% \mathrm{NaOCl}$ as irrigant (S2), in both final irrigation protocols. However, the number of cultivable bacteria significantly decreased in PUA group, with $98.37 \%$ reduction percentage when comparing with CNI group, which only reduced $23.56 \%$. Therefore, cultivable bacteria significantly reduced when comparing the protocols. After S3, PUA and CNI group resulted in
$80 \%$ and $30 \%$ root canals free of cultivable bacteria, respectively. These results corroborate the findings in previous studies, ${ }^{28,29}$ which also observed a higher antibacterial effect using the irrigation solution associated with ultrasonic activation due to the cavitation promoted by the action of ultrasound on the irrigant. ${ }^{13}$

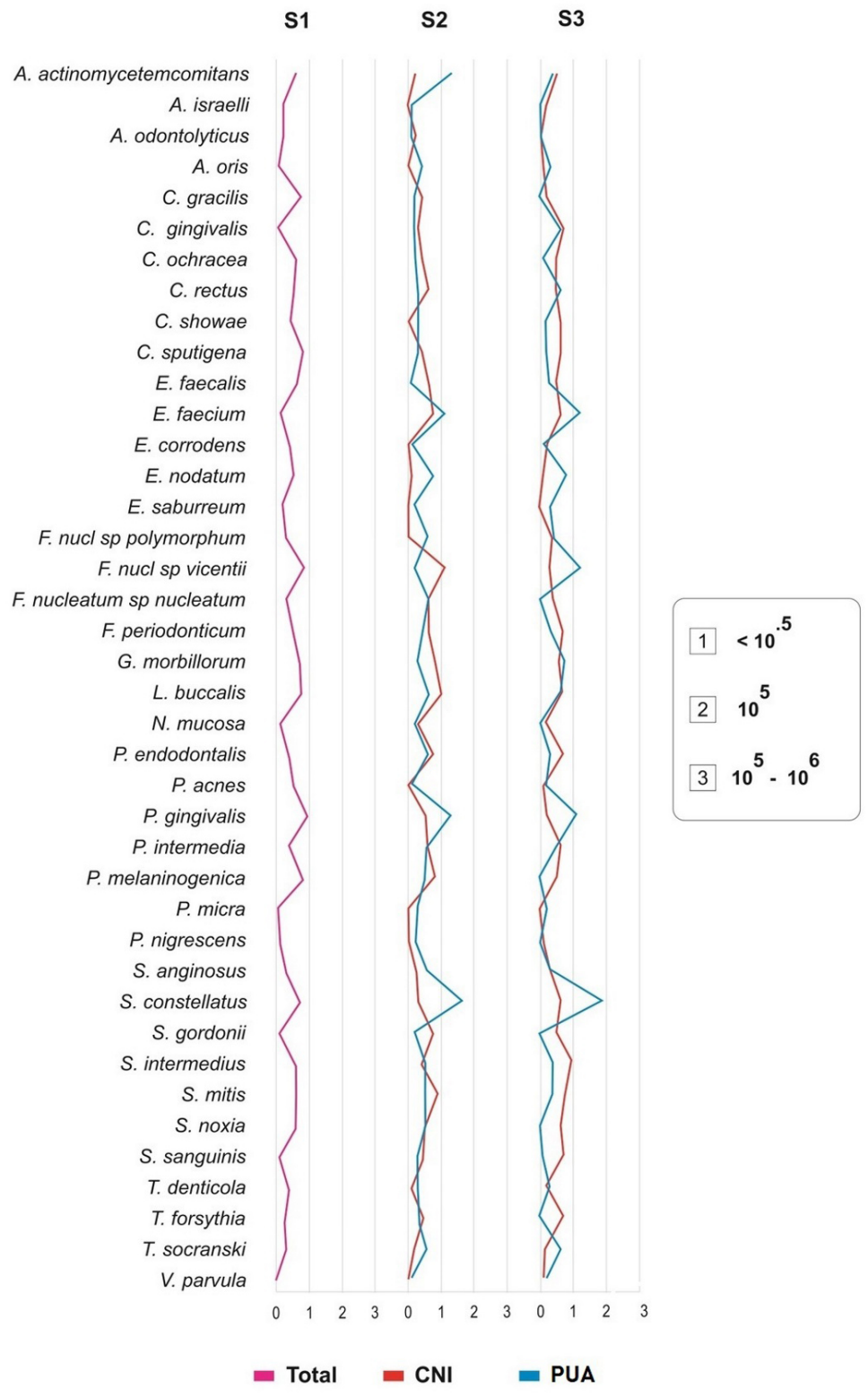

Figure 5- Bacterial levels before root canal treatment (S1), after instrumentation with $\mathrm{PUA}^{\star}$ or $\mathrm{CNI}{ }^{\star \star}(\mathrm{S} 2)$ and after final irrigation using EDTA with PUA or CNI (S3)

Table 3- Effectiveness of PUA and CNI protocol in reducing periapical lesion volume in primary endodontic infection [Different letters mean statistically significant differences $(\mathrm{p}<0.05)$. Uppercase letters indicate difference in the line (intra-groups) and lowercase letters indicate difference in the column (inter-groups)]

\begin{tabular}{ccc}
\hline Final Irrigation Protocol & CBCT Analysis & $\begin{array}{c}\text { Initial Periapical Lesion Volume } \\
\text { Volume }\end{array}$ \\
\hline $\mathrm{PUA}^{*}$ & $63.3 \pm 67.4^{\mathrm{Aa}}$ & $39.3 \pm 27.9^{\mathrm{Ba}}$ \\
$\mathrm{CNI}^{* *}$ & $88.0 \pm 72.2^{\mathrm{Aa}}$ & $39.0 \pm 45.3^{\mathrm{Ba}}$ \\
\hline
\end{tabular}

${ }^{*}$ PUA - Passive Ultrasonic Activation; ${ }^{* *} \mathrm{CNI}$ - Conventional Needle Irrigation 
Although the literature shows PUA activation time may range from 20 seconds to 5 minutes, ${ }^{28-30}$ it has also demonstrated that a 30-second ultrasonic activation seems to be sufficient to achieve cleaner canals. ${ }^{31,32}$ The protocol established in this study was 2 cycles of 30 seconds of ultrasonic activation with $2.5 \% \mathrm{NaOCl}$ while $17 \%$ EDTA was activated for 1 minute straight, resulting in a total of 2 minutes of ultrasonic activation. According to Van der Sluis, et al. ${ }^{33}$ (2009), the refreshment of the irrigant substance aids on dental debridement. Besides, emphasizing the importance of using both substances to remove smear layer is relevant, once it is known that neither $\mathrm{NaOCl}$ nor EDTA can alone eliminate both organic and inorganic portion of the smear layer. ${ }^{34}$

Some authors have drawn attention to the polymicrobial nature of endodontic infections. 9,35,36 Supporting this statement, our study showed a mean of 9.6 species per root canal in the baseline (S1) using the checkerboard DNA-DNA hybridization method. $S$. constellatus was the most prevalent species before endodontic treatment, detected in $50 \%$ of all initial samples, followed by $E$. faecalis ( $45 \%), F$. nucleatum SP $(45 \%), P$. gingivalis (45\%), P. melaninogenica (45\%), and S. intermedius (45\%).

S. constellatus, S. intermedius, and E. faecalis remained in more than $45 \%$ of root canals in both groups, PUA e CNI, after endodontic treatment (S3). Likewise, these findings demonstrate that Grampositive bacteria might be more resistant to endodontic treatment, as in Rôças and Siqueira ${ }^{35}$ (2011). Besides, S. constellatus and $S$. intermedius are highly prevalent in primary endodontic infections, and, despite being commensal oral bacteria, they may be related to acute and invasive diseases when associated. ${ }^{37} \mathrm{E}$. faecalis is also highly prevalent in primary endodontic infections due to its capacity to deeply penetrate into dentinal tubules $^{38}$ and its resistance to intracanal medication, thus being considered a microorganism highly resistant to endodontic treatment. Although enterococci are not considered highly virulent microorganisms, some authors suggest their pathogenicity can be more related to its resistance to several antimicrobial agents. ${ }^{39,40}$ Moreover, synergistic interactions must be considered since their collective pathogenicity probably resulted from a combination of virulence factors. ${ }^{36}$ The authors understand the similarity between groups, considering the checkerboard results (bacterial species identification), and therefore, a supposed similarity of our results to the CFU data may be questioned. This disparity between our outcomes (CFU $\times$ checkerboard) might be explained by two reasons: 1 - the outcome is different due to the specificity of the analysis, or 2due to the sample size used for checkerboard analysis. As the checkerboard was a complementary analysis in this study, one might assume it did not influence negatively the study. On the other hand, checkerboard, when used to detect microbiological profile between different types of endodontic infection, must be used as the main outcome and included in the sample size.

In this study, the primary outcome measurement was defined by СВCT analysis, which suggested both groups were effective in reducing periapical lesion. Moreover, both treatments resulted in clinical success considering the absence of pain, mobility, and fistula. As the power estimation to include patients considered the volume assessment, the above clinical considerations might be underpowered for granting such comparison, despite being an important outcome for the proposed treatments.

\section{Conclusion}

In conclusion, both treatments significantly decreased the number of bacterial species when compared with the initial sample. However, no statistical difference in the total microbial load between PUA and CNI groups was detected. The number of cultivable anaerobic bacteria significantly decreased using PUA; bacterial composition and number of bacterial species found after using CNI or PUA was similar.

\section{Compliance with ethical standards}

\section{Conflict of interest}

The authors deny any conflicts of interest related to this study.

\section{Funding}

The study was supported by the Brazilian agencies FAPESP (grant No. 2014/25789-9).

\section{Ethical approval}

All procedures performed in studies involving human participants were in accordance with the ethical standards of the institutional and/or national research 
committee and with the 1964 Helsinki declaration and its later amendments or comparable ethical standards.

\section{Informed consent}

Informed consent was obtained from all individual participants included in the study.

\section{References}

1- Rôças IN, Siqueira JF Jr. Root canal microbiota of teeth with chronic apical periodontitis. J Clin Microbiol. 2008;46(11):3599-606.

2- Nakamura VC, Cai S, Candeiro GTM, Ferrari PH, Caldeira CL, Gavini G. Ex vivo evaluation of the effects of several root canal preparation techniques and irrigation regimens on a mixed microbial infection. Int Endod J. 2013;46(3):217-24.

3- Siqueira JF Jr, Rôças IN. Clinical implications and microbiology of bacterial persistence after treatment procedures. J Endod. 2008;34(11):1291-301.e3.

4- Haapasalo M, Shen Y, Qian W, Gao Y. Irrigation in endodontics. Dent Clin North Am. 2010;54(2):291-312.

5- Valera MC, Maekawa LE, Oliveira LD, Jorge AO, Shygei E, Carvalho CA. In vitro antimicrobial activity of auxiliary chemical substances and natural extracts on Candida albicans and Enterococcus faecalis in root canals. J Appl Oral Sci. 2013;21(2):118-23.

6- Carvalho AS, Camargo CH, Valera MC, Camargo SE, Mancini MN. Smear layer removal by auxiliary chemical substances in biomechanical preparation: a scanning electron microscope study. J Endod. 2008;34(11):1396-400.

7- Vianna ME, Horz HP, Gomes BP, Conrads G. In vivo evaluation of microbial reduction after chemo-mechanical preparation of human root canals containing necrotic pulp tissue. Int Endod J. 2006;39(6):484-92. 8- Cardoso FG, Ferreira NS, Martinho FC, Nascimento GG, Manhães LR Jr, Rocco MA, et al. Correlation between volume of apical periodontitis determined by cone-beam computed tomography analysis and endotoxin levels found in primary root canal infection. J Endod. 2015;41(7):1015-9.

9- Ferreira NS, Martinho FC, Cardoso FG, Nascimento GG, Carvalho CA, Valera MC. Microbiological profile resistant to different intracanal medications in primary endodontic infections. J Endod. 2015;41(6):824-30.

10- Neves MA, Provenzano JC, Rôças IN, Siqueira JF Jr. Clinical antibacterial effectiveness of root canal preparation with reciprocating single-instrument or continuously rotating multi-instrument systems. J Endod. 2016;42(1):25-9.

11- Ricucci D, Siqueira JF Jr, Bate AL, Pitt Ford TR. Histologic investigation of root canal-treated teeth with apical periodontitis: a retrospective study from twenty-four patients. J Endod. 2009;35(4):493-502.

12- Boutsioukis $C$, Lambrianidis T, Verhaagen B, Versluis $M$, Kastrinakis $E$, Wesselink PR, et al. The effect of needle-insertion depth on the irrigant flow in the root canal: evaluation using an unsteady computational fluid dynamics model. J Endod. 2010;36(10):1664-8. 13- Van der Sluis LW, Versluis M, Wu MK, Wesselink PR. Passive ultrasonic irrigation of the root canal: a review of the literature. Int Endod J. 2007;40(6):415-26.

14- Huque J, Kota K, Yamaga M, Iwaku M, Hoshino E. Bacterial eradication from root dentine by ultrasonic irrigation with sodium hypochlorite. Int Endod J. 1998;31(4):242-50.

15- Siqueira JF Jr, Machado AG, Silveira RM, Lopes HP, Uzeda M. Evaluation of the effectiveness of sodium hypochlorite used with three irrigation methods in the elimination of Enterococcus faecalis from the root canal, in vitro. Int Endod J. 1997;30(4):279-82.
16- Alves FR, Almeida BM, Neves MA, Moreno JO, Rôças IN, Siqueira JF Jr. Disinfecting oval-shaped root canals: effectiveness of different supplementary approaches. J Endod. 2011;37(4):496-501.

17- Koletsi D, Pandis N, Polychronopoulou A, Eliades T. Mislabeling controlled clinical trials (CCTs) as "randomized clinical trials (RCTs)" in dental specialty journals. J Evid Based Dent Pract. 2012;12(3):124-30. 18- Nakamura VC, Pinheiro ET, Prado LC, Silveira AC, Carvalho AP, Mayer MP, et al. Effect of ultrasonic activation on the reduction of bacteria and endotoxins in root canals: a randomized clinical trial. Int Endod J. 2018;51( Suppl 1):e12-e22.

19- Beus C, Safavi K, Stratton J, Kaufman B. Comparison of the effect of two endodontic irrigation protocols on the elimination of bacteria from root canal system: a prospective, randomized clinical trial. J Endod. 2012;38(11):1479-83.

20- Siqueira JF Jr, Rôças IN. Diversity of endodontic microbiota revisited. J Dent Res. 2009;88(11):969-81.

21- Siqueira JF Jr, Rôças IN. Exploiting molecular methods to explore endodontic infections: part 2 - redefining the endodontic microbiota. J Endod. 2005;31(7):488-98

22- Cavalli D, Toia CC, Flores Orozco EI, Khoury RD, Cardoso FG, Alves $M C$, et al. Effectiveness in the removal of endotoxins and microbiological profile in primary endodontic infections using 3 different instrumentation systems: a randomized clinical study. J Endod. 2017;43(8):1237-45.

23- Möller AJ. Microbiological examination of root canals and periapical tissues of human teeth. Methodological studies. Odontol Tidskr. 1966;74(5):Suppl:1-380.

24- Socransky SS, Smith C, Martin L, Paster BJ, Dewhirst FE, Levin AE. "Checkerboard" DNA-DNA hybridization. Biotechniques. 1994;17(4):788-92.

25- Al-Jadaa A, Paqué F, Attin T, Zehnder M. Necrotic pulp tissue dissolution by passive ultrasonic irrigation in simulated accessory canals: impact of canal location and angulation. Int Endod J. 2009;42(1):59-65.

26- Ahmad M, Pitt Ford TR, Crum LA, Walton AJ. Ultrasonic debridement of root canals: acoustic cavitation and its relevance. J Endod $1988 ; 14(10): 486-93$

27- Ahmad M, Pitt Ford TJ, Crum LA. Ultrasonic debridement of root canals: acoustic streaming and its possible role. J Endod $1987 ; 13(10): 490-9$.

28- Cachovan G, Schiffner U, Altenhof S, Guentsch A, Pfister W, Eick S. Comparative antibacterial efficacies of hydrodynamic and ultrasonic irrigation systems in vitro. J Endod. 2013;39(9):1171-5.

29- Almeida AP, Souza MA, Miyagaki DC, Dal Bello Y, Cecchin D, Farina AP. Comparative evaluation of calcium hypochlorite and sodium hypochlorite associated with passive ultrasonic irrigation on antimicrobial activity of a root canal system infected with Enterococcus faecalis: an in vitro study. J Endod. 2014;40(12):1953-7.

30- Gu L, Kim JR, Ling J, Choi KK, Pashley DH, Tay FR. Review of contemporary irrigant agitation techniques and devices. J Endod. 2009;35(6):791-804.

31- Sabins RA, Johnson JD, Hellstein JW. A comparison of the cleaning efficacy of short-term sonic and ultrasonic passive irrigation after hand instrumentation in molar root canals. J Endod. 2003;29(10):674-8.

32- Siqueira JF Jr, Alves FR, Rôças IN. Pyrosequencing analysis of the apical root canal microbiota. J Endod. 2011;37(11):1499-503.

33- Van der Sluis L, Wu MK, Wesselink P. Comparison of 2 flushing methods used during passive ultrasonic irrigation of the root canal. Quintessence Int. 2009;40(10):875-9.

34- Guerisoli DM, Marchesan MA, Walmsley AD, Lumley PJ, Pecora JD. Evaluation of smear layer removal by EDTAC and sodium hypochlorite with ultrasonic agitation. Int Endod J. 2002;35(5):418-21.

35- Rôças IN, Siqueira JF Jr. In vivo antimicrobial effects of endodontic treatment procedures as assessed by molecular microbiologic techniques. J Endod. 2011;37(3):304-10. 
36- Rôças IN, Siqueira JF Jr, Debelian GJ. Analysis of symptomatic and asymptomatic primary root canal infections in adult Norwegian patients. J Endod. 2011;37(9):1206-12.

37- Navratilova L, Bardon J, Novotny R, Zatloukal J, Jakubec P, Kolek V, et al. The Streptococcus milleri group in chronic obstructive pulmonary disease. Biomed Pap Med Fac Univ Palacky Olomouc Czech Repub. 2016;160(3):378-84.
38- Siqueira JF Jr, Uzeda M, Fonseca ME. A scanning electron microscopic evaluation of in vitro dentinal tubules penetration by selected anaerobic bacteria. J Endod. 1996;22(6):308-10.

39- Poyart C, Quesnes G, Trieu-Cuot P. Sequencing the gene encoding manganese-dependent superoxide dismutase for rapid species identification of enterococci. J Clin Microbiol. 2000;38(1):415-8.

40- Rôças IN, Siqueira JF Jr, Santos KR. Association of Enterococcus faecalis with different forms of periradicular diseases. J Endod. $2004 ; 30(5): 315-20$. 